
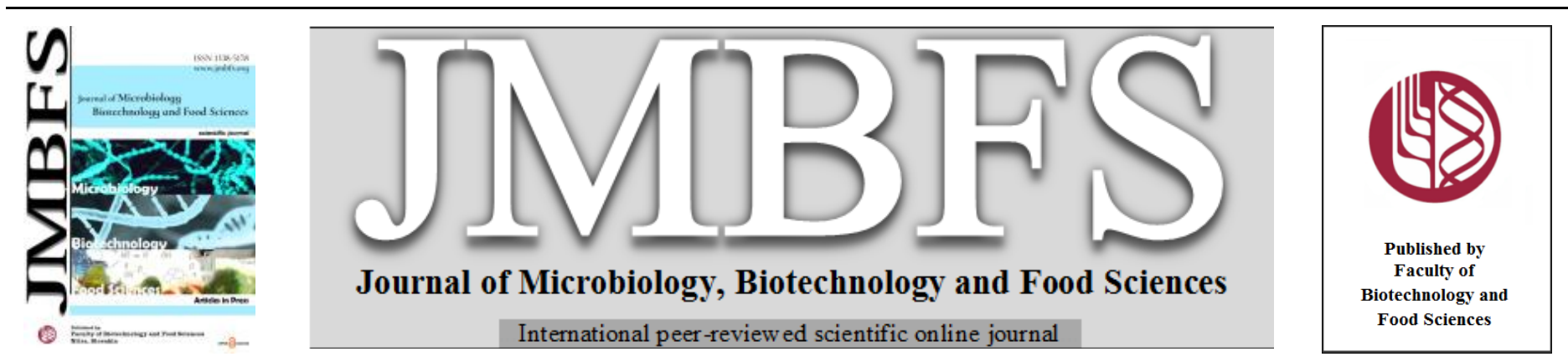

\title{
PREDICTING SHELF LIFE OF CHICKEN BURGER PRODUCED FROM SURIMI UNDER COMBINED USE OF THYME ESSENTIAL OIL AND MODIFIED ATMOSPHERE PACKAGING
}

\author{
Azadeh Rashidimehr ${ }^{l}$, Ali Fazlara ${ }^{* 1}$, Mehdi Zarei ${ }^{1}$, Mehdi PourMehdi $^{1}$, Mohammad Noshad $^{2}$
}

$\operatorname{Address(es):~}$

${ }^{1}$ Shahid Chamran University of Ahvaz, Faculty of Veterinary Medicine, Department of Food Hygiene, Ahvaz, Khuzestan, Iran, Phone number: +989123091813.

${ }^{2}$ Agricultural Sciences and Natural Resources University of Khuzestan, Department of Food Science and Technology, Mollasani, Khuzestan, Iran.

*Corresponding author: $\underline{\text { a.fazlara@ } \mathrm{scu} . \mathrm{ac} . \mathrm{ir}}$

https://doi.org/10.55251/jmbfs.1662

\section{ARTICLE INFO}

Received 13. 5. 2019

Revised 26. 8. 2021

Accepted 3. 9. 2021

Published 1.2. 2022

Regular article

OPEN $\partial_{\text {ACCESS }}$

\section{ABSTRACT}

In the present research, the mixed use of thyme essential oil (EO) and Modified Atmosphere Packaging (MAP) treatments is studied to increase the quality and the shelf life of burgers prepared from surimi and chicken meat which were refrigerated at $2^{\circ} \mathrm{C}$ for 27 days. Obviously, there was a significant difference $(\mathrm{p}<0.001)$ between chemical and microbiological analyses of burger treated with thyme $\mathrm{EO}$, free of EOs and packed in the air or in the MAP. So burger shelf life was extended by 18 days with the combination of MAP packaging with thyme EO. Also, Artificial Neural Network (ANN) was used to forecast the shelf life of produced burgers under thyme essential oil and MAP influence. The model obtained from ANN has a higher $\left(\mathrm{R}^{2}\right)$ and less RMSE in predicting the shelf life of produced burgers under the combined use of thyme essential oil and MAP.

Keywords: Artificial Neural Network, Consolidated burgers, Modified Atmosphere Packing, Thyme

\section{INTRODUCTION}

Food spoilage is a change within the food product unacceptable for the consumer in the sensory point of view, may be due to physical and chemical changes or microbial growth and food metabolism. So in order to decline the microbial acceleration or chemical processes of spoilage, meat products are stored in cool places. Furthermore, gas-devoid atmosphere or altered gas composition is used for packing meat products (Van Haute et al., 2017). Surimi, which is a Japanese word for condensed and wet muscle myofibrils, is a product produced from both marine and freshwater fish. It is prepared by deboning, washing, mincing and fixating the meat with cryoprotectants. Next, water-soluble compounds, fat, blood, enzymes, sarcopelasmic proteins, odorants and flavoring compounds are separated during special fish washing operations (Dey and Dora, 2010). Surimi is a main component in the desired food production in many countries since it improves the efficiency, easy mixing of stabilizers, flexibility in the preparation of food and the suitability of the compound (Karthikeyan et al., 2006). Surimi is not normally consumed directly and it is used to produce other products (Bentis et al., 2005).

Meat is a significant part of nutrient-rich muscle food, reasonable for human utilization, in this way, its protection requires particular packaging systems till utilization (Soni et al., 2018). The enthusiasm for natural methods that can make food more secure, evading the utilization of chemical additives or preservatives, has expanded the examination on these items. In such manner, essential oils (EOs) are notable for their additive properties. These substances and their segments are utilized in food for their antiviral, antibacterial, antifungal, antioxidant, and anticarcinogenic properties (Marotta et al., 2016). Zataria multiflora Boiss. or again thyme belongs to Labiatae family and geographically, it resides only in south and central regions of Iran, Pakistan and Afghanistan as a wild plant. This plant is similar to garden thyme (Thymus vulgaris) chemically and medically and is a notable and generally considered plant for its therapeutic properties and it is also called Shirazi thyme. Carvacrol, thymol, linal, and paracymon consist 2, 25, 61 and 2 percent of the essential oils which are derived from the dry matter sample of the plant; thymol and carvacrol are the main ingredient of phenolic compounds and the paracymon is the main factor in non-phenolic compounds of Shirazi thyme essence. Thymol and Shirazi thyme EO have strong antimicrobial influence in anaerobic situations, applying their inhibiting effect by tearing the outer lipopolysaccharide layer of the bacterial wall with the phenolic compounds within the essence (Çoban and Keleștemur, 2016) (Sajed et al., 2013). It is notable that the antimicrobial strength of EOs in food systems is commonly diminished when contrasted with in vitro work, as the nearness of proteins, fats, salts, sugars, and
$\mathrm{pH}$ unequivocally impact the viability of these operators (Burt, 2004). Likewise, bigger measures of EOs are required in food frameworks, accordingly genuinely meddling with the last organoleptic attributes (Busatta et al., 2008). Many examinations on the effect of EOs in food systems have been accounted for in the writing (Stevanović et al., 2018). Various reports are known in the writing on the impacts of EOs or their constituents (for example carvacrol, thymol and so on.) on the shelf life of different food items, including: meat, and its products (Skandamis and Nychas, 2002, Zamuz et al., 2018), poultry and its products (Jayawardana et al., 2015, Behnam and Aliakbarlou, 2014), fresh fish, fish processing and cephalopods (Daniel et al., 2014, Frangos et al., 2010, Giarratana et al., 2016). Due to the increasing consumption of readily-made foods such as burgers and their popularity in the general population, the aim of present research is to replace surimi within the burger formula to optimize the burger formula with various surimi proportions in order to increases the consumption of fish. On the other hand, the current study aims to extend burger's shelf life using the Modified Atmosphere Packing (MAP) method and thyme EO. So this investigation was conducted to extend the shelf life in conventional packing and MAP with a gas mix of $0 \% \mathrm{O}_{2}$, $65 \% \mathrm{CO}_{2}$ and $35 \% \mathrm{~N}_{2}$ with natural essential oil of Shirazi thyme.

\section{MATERIAL AND METHODS}

\section{The chicken minced meat and surimi preparations}

Fresh chicken meat was purchased on the day of production from the market (Ahvaz, Khuzestan Province, Iran), deboned and washed completely, then minced by a machine with $4 \mathrm{~mm}$ diameter pores (EG-1200-EBS, Jahan Ava, Iran) and kept in plastic bags of polyethylene at $-18^{\circ} \mathrm{C}$. Fresh silver carp (Hypophthalmichthys molitrix), (Ahvaz, Khuzestan Province, Iran) was purchased and transferred within $30 \mathrm{~min}$ period to the laboratory with fish to ice ratio of $1: 1$. Then viscera were exhausted and the fish was beheaded and filleted. Then the fish fillets were sluiced with cold water and minced by a grinder (Jahan Ava, Iran) and equipped with a disk with a $4 \mathrm{~mm}$ pore diameter. In order to produce surimi gel, the minced meat was washed with a meat/water ratio of 1 to $3(\mathrm{w} / \mathrm{w})$. Washing was performed with $4^{\circ} \mathrm{C}$ chilly water and continuous stirring in 10 minutes in a vapid chamber. The sluiced minced fish were sifted via 4 cheesecloth layers and afterward it was dehydrated under pressure. This procedure was repeated for two times. A $0.5 \%$ $\mathrm{NaCl}$ (Merck, Darmstadt, Germany) solution was used to complete the third step of washing with a proportion of 1 to $3(\mathrm{w} / \mathrm{w})$ ratios for chopped fish to a $\mathrm{NaCl}$ aqueous solution. Then, the fillets were dehydrated; protected by addition of 
cryoprotectants [Sucrose 3\% (Merck, Darmstadt, Germany) and Sorbitol 3\% (Merck, Darmstadt, Germany)] and mixed in the stirrer for 60 seconds. Finally, surimi was bundled in polyethylene plastic sacks and bespoke at $-18{ }^{\circ} \mathrm{C}$ (Jafarpour and Gorczyca, 2008) (Rawdkuen et al., 2009).

\section{Preparation of combined burgers and treatments}

The Response surface methodology (RSM), (Design Expert 6.0.2 software) was applied to find the optimum formula. Then, the results were analyzed and optimized based on the sensory evaluation results and a burger formula was selected which was containing $63 \%$ surimi and $37 \%$ chicken minced meat and all microbial and chemical characteristics and it was performed on the mentioned burger formula. After partial thawing of minced chicken meat and surimi, it was mixed in a blender (Gosonic, Turkey) for one minute and then the ingredients needed to prepare a burger including onions, soy, spices (black pepper and garlic powder), and salt. In order to prevent the growth of Clostridium botulinum, 125 ppm nisin (Sigma Aldrich, UK), [dissolving a suitable amount of nisin powder in sterilized $0.02 \mathrm{~N} \mathrm{HCl}$ solution to prepare a nisin solution] were added to the mil for two more minutes. Thyme (500 ppm) (Barij Essence, Iran) dilution was also selected by sensory evaluation. For sensory evaluation, the burgers were fried in the same cooking method (at $170^{\circ} \mathrm{C}$ to achieve an internal end-point temperature of $72^{\circ} \mathrm{C}$ (Heydari et al., 2016) in traditional frying method for serving burgers in Iran). The burgers were prepared with the optimized of burger (63\% surimi and $37 \%$ chicken minced) at 0 day storage. Sensory experiments were performed on the product immediately after production. To evaluate the overall acceptance of the products, trained panel evaluations have been used to rate the taste and smell burgers with three different concentrations of 100, 300, and 500 ppm. Burgers scored with a concentration of 500 ppm the most points.

The burgers were subdivided into 2 groups (aerobic packing and MAP), which included two subgroups of control and thyme EO. In order to create a regular burger, burgers were produced in $5 \mathrm{~cm}$ diameter and $1 \mathrm{~cm}$ thickness by conventional burger-maker. The burgers were packed in plastic bags of HDPE (high density polyethylene) and kept in cold $\left(2^{\circ} \mathrm{C}\right)$ before the start of testing. Sampling was performed to determine microbial and chemical indices at $0,3,6,9,12,15,18,21$, 24 and 27 days; and all of this processes were done in a completely random method. These trials were repeated three times.

\section{Sensory evaluation}

The panel included seven experienced evaluators (trained in the laboratory) for sensory evaluation. All evaluators had already attended in instructional meeting to get acquainted with the sensory attributes of the cooked burger. Panelists assessed the color, taste, smell and overall quality. The 9-point scale was used for each attribute. The scale points were: excellent: 9; very good: 8; good: 7; and a score of 6 for acceptability. Values equal to a score of 5 are the threshold of acceptance and 1-4 scores were considered unacceptable (Spinelli et al., 2015).

\section{Microbiological analysis}

For the analysis of microbial characteristics, $10 \mathrm{~g}$ of the burger sample was added to the $90 \mathrm{ml}$ distilled of $0.1 \%$ peptone-water, sterilized and then put in a Stomacher Lab Blender (Interscience Bag Mixer, China) to homogenize the mixture for 3 minutes. Then the Dilutions were prepared. The Total Viable Counts (TVC) was performed using Plate Count Agar (PCA), (Merck, Darmstadt, Germany), (APHA, 2015), which was incubated at $37^{\circ} \mathrm{C}$ for 48 hours. The psychrotrophic bacteria counts (APHA, 2015), were also performed after incubation with PCA during 10 days at $7^{\circ} \mathrm{C}$. For lactic acid bacteria count (LAB), (Doulgeraki et al., 2010), de Man Rogosa Sharpe agar (MRS), (Q Lab, Canada) was incubated for 3 days at $30^{\circ} \mathrm{C}$. sulfite-polymyxin-sulfadiazine agar (Merck, Darmstadt, Germany) was also used to determine the sulfite-reducing Clostridia amount (Selani et al., 2016) which was incubated at $30^{\circ} \mathrm{C}$ for 48 hours, overlayed with the same medium and incubated in plastic anaerobic jars by AnaeroGen sachet (Anaerobic gas pack A, Merck, Darmstadt, Germany). For mold and yeast count, Yeast Extract Agar (Merck, Darmstadt, Germany) was incubated for 5 days at $25^{\circ} \mathrm{C}$ (Petrou et al., 2012). The microbiological investigations were conducted three times in three unique batches.

\section{Chemical analysis}

The $\mathrm{pH}$ was determined using a $\mathrm{pH}$ meter (Sartorius, USA), (Namir et al., 2015) Measurement of Total Volatile Base Nitrogen (TVB-N) was measured by Ojagh et al. (2010) method. Thiobarbituric acid (TBA) was estimated regarding malondialdehyde in per $\mathrm{kg}$ of burger. Measuring turbidity was performed according to the method of Ojagh et al. (2010) and by using a spectrophotometer. Peroxide value (PV) was calculated by the AOAC (2010) method. All chemical analyses were performed in triplicate.

\section{Artificial neural networks modeling}

An artificial neural network modeling consists of a set of neurons with internal communication between each other, which can estimate outcomes based on the information and input data. The studied network was a multi-layered Perceptron (MLP) network. The training algorithms of the Levenberg-Marquardt algorithm (LM) were used to synchronize artificial neural network weights, which is a standout amongst the most broadly applicable algorithms since it provides a quick network training process and limits the level of errors. Overtraining is one of the issues that we experience while preparing a neural network. This way, the amount of error is acceptable while training a network, but during assessments, the amount of network error is much more than a training data error. There are two different ways to abstain from overtraining: 1 . A quick stop of training; 2 . choosing the most reduced number of neurons in the confidential layer. Here, we used the second method, as represented in figure 1. Therefore, by considering the main goal to prepare the network, firstly data was randomly separated into three sections as: $60 \%, 20 \%$ and $20 \%$ of the data which this data were used for training, evaluation, and network testing, respectively. Amid network instruction and the educational procedure were ruptured when the error expanded among the training and appraisal data.

In order to modeling neural network, MATLAB software encoding (Matlab, 2017b) was used. In order to select the best model, root means square error (RMSE) and correlation coefficient $\left(\mathrm{R}^{2}\right)$ was used to evaluate and compare the performance of artificial neural networks in predicting the shelf-life of the produced burgers under thyme essential oil and MAP impact. The equations for each statistics are presented as follows:

$\mathrm{RMSE}=\sqrt{\frac{\sum_{\mathrm{i}=1}^{\mathrm{n}}\left(\mathrm{o}_{\mathrm{i}}-\mathrm{p}_{\mathrm{i}}\right)^{2}}{\mathrm{n}}}$

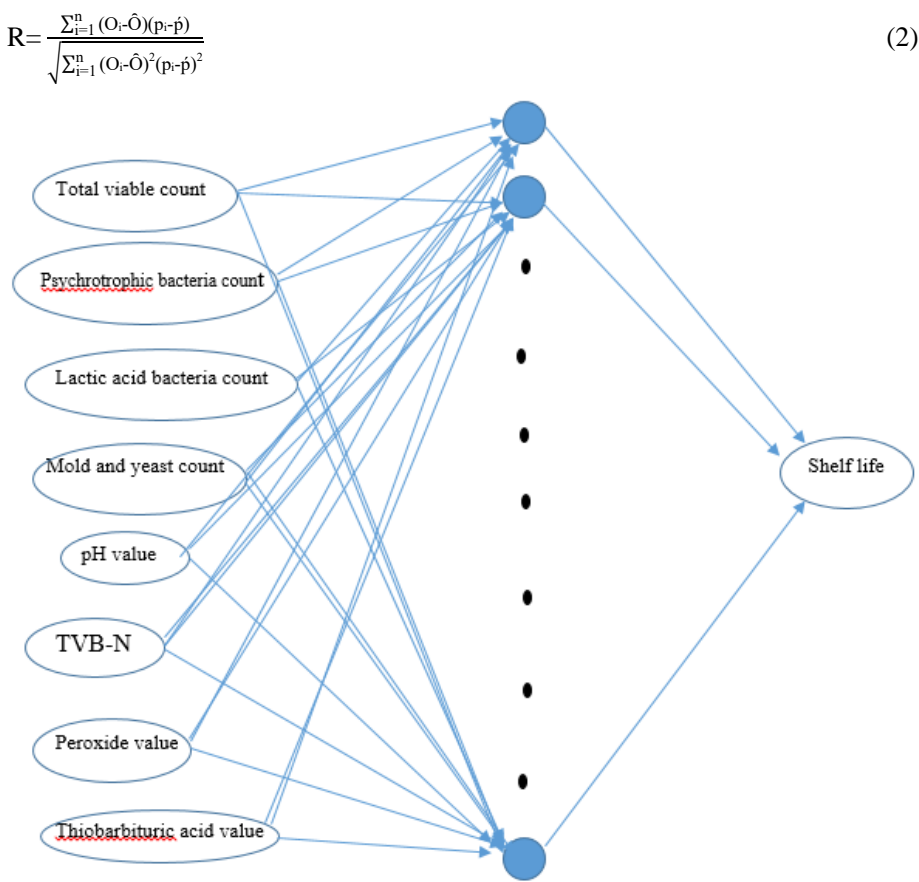

Figure 1 Schematic description where TVC, Psychrotophic bacteria count, LAB count, Mold and Yeast count, $\mathrm{pH}$, TVB-N, thiobarbituric acid, PV are independent input variables and Shelf life is the dependent output variable of ANN. Statistical analysis

Data were analyzed descriptively and analytically using SPSS 23 software. Data were analyzed by ANOVA test and repeated and measures the bilateral variance analysis. $\alpha=0.05$ was considered as a meaningful level for statistical judgment.

\section{RESULTS AND DISCUSSION}

Thyme EO effect with or without a map on the microbial shelf life of chicken burger which is optimized with surimi

\section{Total viable count}

According to figure 2A, TVC of burgers increased in all days of the storage under different packing conditions with or without thyme EO ( $\mathrm{c} 0.001)$. Maximum count of TVC was $10^{7} \log$ CFU/g in fresh and frozen fish. Initial TVC was about 4.05 (aerobic without thyme EO), 4.4 (aerobic + thyme EO), 4.38 (MAP + without thyme EO) and 4.38 (MAP + thyme EO) $\log$ CFU/g, which under the storage days, these amounts reached to $8.78,8.39,6.18$, and $4.86 \log \mathrm{CFU} / \mathrm{g}$, respectively. In the 
current scrutiny, the total TVC value was higher than the standard level (7 Log $\mathrm{CFU} / \mathrm{g}$ ) in aerobic packing without thyme EO on the 9th storage day as well as the aerobic packing with thyme EO on the 15th storage day. Therefore, various packing conditions and essential oils had an inhibitory impact TVC in burger specimens. Muhlisin et al. (2013) also suggested that the addition of $30 \%$ of carbon dioxide to the pre-cooked hamburger patties delays the growth of TVC and this effect is increased by adding rosemary extracts and sodium acetate. In another study, antibacterial effects of thyme EO was due to different phenolic substances, namely, thymol and carvacrol (Sarıçoban and Yilmaz, 2014).

\section{Psychrotrophic bacteria count}

According to the figure $2 \mathrm{~B}$, the total amount of psychrotrophic bacteria has changed by the time $(\mathrm{p}<0.001)$. Initial count of psychrotrophic bacteria was 4.41 (aerobic without thyme EO), 4.48 (aerobic + thyme EO), 4.62 (MAP + withou thyme EO) and 4.6 (MAP + thyme EO) $\log$ CFU/g, which these amounts reached to $8.79,8.33,7.02$ and $7.00 \mathrm{log} \mathrm{CFU} / \mathrm{g}$ in storage period, respectively. Through Praneetha et al. (2015) research about the, pre-heated fish fingers which was made from roho fish (Labeo rohita)), was stored for 11 days at $4^{\circ} \mathrm{C}$. The overall TVC count and the total number of psychrotrophic bacteria from the initial sample count increased from $5.68 \times 10^{2} \mathrm{CFU} / \mathrm{g}$ to $1.72 \times 10^{5} \mathrm{CFU} / \mathrm{g}$ and from $1.24 \times 10^{2} \mathrm{CFU} / \mathrm{g}$ in the sample to $1.24 \times 10^{5} \mathrm{CFU} / \mathrm{g}$, respectively. In another study, TVC and psychrotrophic bacteria in Sardine patties increased from 2.50 and $2.60 \log \mathrm{CFU} / \mathrm{g}$ to 6.72 and $6.98 \mathrm{log} \mathrm{CFU} / \mathrm{g}$ at the end of the 7 days of storage (Kilinc et al., 2008). If the combination of the MAP with thyme EO has substantially more effectiveness in improving the quality and microbial parameters, then the Thyme EO had a less preservative effect. In fact, thyme EO illustrated to work as a synergist with the MAP

\section{Lactic acid bacteria count}

Changes in the levels of the LAB and their comparisons between treatments during storage time are presented in figure $2 \mathrm{C}$. The $\mathrm{LAB}$ count has changed during the time ( $\mathrm{p}<0.001$ ), with an initial bacterial population of nearly $3 \mathrm{log} \mathrm{CFU} / \mathrm{g}$ that reached to 7.98, 7.59, 7.5 and $7.3 \log \mathrm{CFU} / \mathrm{g}$ for aerobic packing + without thyme $\mathrm{EO}$, aerobic + with thyme EO, MAP + without thyme EO, and MAP + with thyme EO. In Babji and Murthy (2000) study, the count of the LAB in minced goat meat was less than $4.5 \log \mathrm{CFU} / \mathrm{g}$ during 28 storage days in the refrigerator temperature. Also, Fratianni et al. (2010) reported that thyme EO reduces the count of aerobic and LAB in the chicken breast meat. The MAP has affected the reduction of the LAB, which is similar to the results of Patsias et al. (2006). Patsias et al. (2006) indicated that the LAB bacteria population was reduced nearly $1.7 \log \mathrm{CFU} / \mathrm{g}$ under MAP conditions compared to the aerobic packing of preheated chicken specimens. Skandamis and Nychas (2002) also showed the quick growth of LAB in beef under MAP conditions at $5^{\circ} \mathrm{C}$ in comparison with the aerobic packing conditions. Clearly, the use of MAP inhibits the growth of LAB. In this study, $\mathrm{MAP}+$ thyme EO treatment had the maximum effect on the LAB growth

\section{Mold and yeast coun}

The amount of mold and yeast varied over the time ( $\mathrm{p}<0.001$ ), (figure 2D). In this study, the number of mold and yeast in aerobic packing without thyme EO was higher than the standard level (3 Log CFU/g) in comparison with the 9th day and on the 12th day in aerobic packing with thyme EO; but in the MAP without thyme EO, the count of mold and yeast only passed the allowed amount at 12 days of storage. In the Kilinc et al. (2008) the anchovy patties during 5 refrigerated storage days to 5th day, the count of mold and yeast were studied and the count of mold and yeast was less than $10 \mathrm{CFU} / \mathrm{g}$. In another research about goat's minced meat, the count of mold and yeast in the zero-day of storage was about $2 \mathrm{Log}$ CFU/g and reached to $4 \mathrm{Log}$ CFU/g in 28 storage days (Babji and Murthy, 2000). The current results are consistent with Patsias et al. (2006) findings so that these researchers found out that mold and yeast count stays in the range of 3 to $3.6 \log \mathrm{CFU} / \mathrm{g}$ until the 15th day of storage but it increases in aerobic conditions.

Sulfite-reducing clostridia search was at zero during all storage days (data not shown). In Selani et al. (2016) study, the search for sulfite-reducing clostridia was less than $10 \mathrm{CFU} / \mathrm{g}$. In our study, no sulfite-reducing clostridia were isolated.

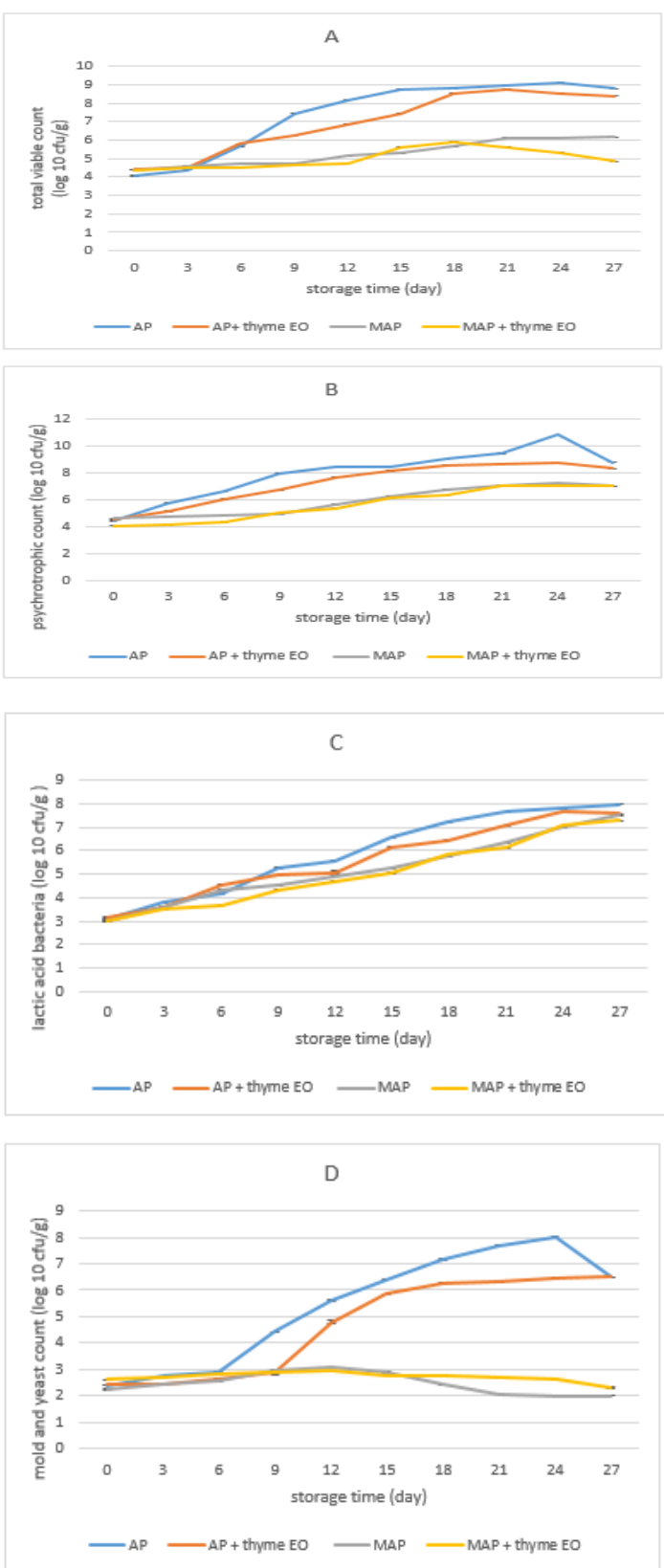

Figure 2 Effect of MAP and thyme oil on (A) TVC (log cfu/g), (B) psychrotrophic count $(\log \mathrm{cfu} / \mathrm{g}),(\mathrm{C}) \mathrm{LAB}(\log \mathrm{cfu} / \mathrm{g})$ and (D) Mold and yeast counts $(\log \mathrm{cfu} / \mathrm{g})$ of burgers at refrigeration temperature. Values are the mean of three replications \pm standard deviation.

The effect of thyme EO with or without a map on the chemical analysis shelf life chicken burger which was optimized with surimi

\section{pH value}

According to figure $3 \mathrm{~A}$, the $\mathrm{pH}$ values changed significantly during storage ( $<0.001$ ). $\mathrm{pH}$ has decreased during storage and it shows a decreasing trend during storage. The highest $\mathrm{pH}$ was observed on zero-day and the lowest $\mathrm{pH}$ was observed on 27th day. In Praneetha et al. (2015) study, fish fingers' $\mathrm{pH}$ declined significantly from 6.95 to 6.44 .The $\mathrm{pH}$ values decreases in 27 storage days; which this reduction could be due to the decrease in oxygen amount by the growth of aerobic microflora and $\mathrm{CO} 2$ release and also it can be due to the sugar contained in the burger, which is used as a cryoprotectant.

\section{Total volatile base nitrogen value}

Total volatile base nitrogen content is the qualitative index of fresh fish and its increase is due to bacterial decomposition. The content of TVB-N in freshly caugh fish is typically between 5 to $20 \mathrm{mg} \mathrm{N}$ per 100 grams, while levels of $30-35 \mathrm{mg} \mathrm{N}$ per 100 grams of meat are totally stored as the acceptance limits for cold stored fish (Köse et al., 2006). In the current research, TVB-N has changed over the time 
( $\mathrm{p}<0.001$ ). It also had an increasing trend during storage, so in the day zero it had the lowest value (figure 3B). The initial value of TVB-N was 7.23 (aerobic without thyme EO), 8.03 (aerobic + thyme EO), 7.55 (MAP + without thyme EO) and 7.81 (MAP + thyme EO) $\mathrm{mg} \mathrm{N}$ in $100 \mathrm{~g}$ and reached a value of 27.05, 22.91, 20.19 and $18.04 \mathrm{mg} N$ per 100 grams at the end of storage days, respectively. In the study of Köse et al. (2006), TVB-N values ranges were from 2. 57 to $54.6 \mathrm{mg} \mathrm{N}$ at $100 \mathrm{~g}$ in UWMP (Unwashed Mince Products), 2.02 to $42.0 \mathrm{mg} \mathrm{N}$ per $100 \mathrm{~g}$ for WMP (Washed Mince Products ) and 4.35 to $92.4 \mathrm{mg} \mathrm{N}$ at any $100 \mathrm{~g}$ in PCMP (PreCooked Mince Products). In another study about fish burger from Catla (Catla Catla) during refrigerated storage, TVB-N of about 17-day storage reached from 2.02 to $4.78 \mathrm{mg} / 100 \mathrm{~g}$. In the same study, the amount of TVB-N did not exceed the acceptable limit during refrigerated storage (Vanitha et al., 2015). In the present study, the rate of TVB-N in the 27-day storage period showed an increasing trend Similar results were obtained by Patsias et al. (2006), which showed that the TVB$\mathrm{N}$ amount in chicken fillet kept under MAP conditions until 16 storage days at $4^{\circ} \mathrm{C}$ was under $20 \mathrm{mg}$ per 100 of meat. Regarding the recent hygienic standards, the acceptable TVB-N limit for fish muscle is $20 \mathrm{mg}$ per $100 \mathrm{~g}$ of burger, according to these standards; it has not exceeded the acceptable limit up to last day of storage The lower TVB-N amount in treated samples by thyme EO may be credited to the antibacterial properties of herbal essence and all the more explicitly to its phenolic constituents, for example, carvacrol and thymol (Zakipour Rahimabadi and Divband, 2012).

\section{Thiobarbituric acid value}

The value of thiobarbituric acid is used to measure lipid oxidation in the product, and its maximum consumption is between 7 and $8 \mathrm{mg}$ of malondialdehyde per kilogram, and higher values indicate quality loss of product (Çoban and Keleştemur, 2016). According to figure 3C, TBA has changed by the pass of time ( $\mathrm{p}<0.001$ ). In the current research, TBA increased during storage but has not reached to the standard limit of 7-8 mg MDA $/ \mathrm{kg}$. In Vanitha et al. (2013) research, TBA of the fish cutlet and fish burger increased from 0.47 to 0.8 and from 0.29 to $0.67 \mathrm{mg} \mathrm{MDA} / \mathrm{kg}$ in the 90th maintenance day, respectively. In another study, the pattern of progress in TBA in fish finger was a steady increase between 0.095 and $1.030 \mathrm{mg} \mathrm{MDA} / \mathrm{kg}$. In the study of Köse $\boldsymbol{e t}$ al. (2006), TBA levels for surimi were sufficient for 15 storage days. Gomes et al. (2003) and Raharjo and Sofos (1993) suggested that TBA index of 1-2 mg MDA/ $\mathrm{kg}$ determines fish based on its high quality. In this investigation, TBA values were lower than $1 \mathrm{mg} \mathrm{MDA} / \mathrm{kg}$ for all treatments over the total refrigerated storage. It is probably due to the relatively low-fat content of burger (surimi).

On the other hand, the lower TBA amount in treated samples by thyme EO may be attributed to the antioxidant effect of phenolic compounds in different parts of plant. (Sarıçoban and Yilmaz, 2014).

\section{Peroxide value}

According to figure 3D, the initial value of $\mathrm{PV}$ of aerobic packing without thyme $\mathrm{EO}$, aerobic packing with thyme EO, without thyme EO and MAP with thyme EO, MAP values were $0.18,0.17,0.16$ and $0.15 \mathrm{meq} / \mathrm{kg}$ of lipid, respectively; which reached to $8.58,2.61,2.82$ and $33.1 \mathrm{meq} / \mathrm{kg}$ of lipid in the maintenance expiration. In the present examination, PV increased in all groups from 0 to 21 days and then it declined till the termination time. In qualitative fish, $\mathrm{PV}$ is expected to be below $5 \mathrm{meq} / \mathrm{kg}$ lipids (Sarıçoban and Yilmaz, 2014). PV exceeded the allowed amount $(5 \mathrm{meq} / \mathrm{kg})$ in aerobic packing without thyme EO and aerobic packing with thyme EO in the 12th and 21st days. Similar findings have been obtained by Coban and Keleştemur (2016) in catfish burger which was treated with thyme. These findings also show the inhibitory effect of thyme EO on burger spoilage. The lower PV amount (from the 20th day of storage) can be due to the hydroperoxide decomposition. Hydroxides break down into a wide assortment of decomposition products, such as aldehydes, in several steps (Chaijan et al., 2006). The decreased PV in treated samples by thyme EO may be attributed to carvacrol, thymol as well as antioxidant effects (Zakipour Rahimabadi and Divband, 2012).

Table 1 Correlation coefficients and RMSE for prediction of neural network

\begin{tabular}{|c|c|c|c|c|c|c|c|}
\hline \multirow{2}{*}{ Parameter } & \multirow{2}{*}{ Architecture } & \multicolumn{2}{|c|}{ Activation function } & \multicolumn{2}{|c|}{ training } & \multicolumn{2}{|c|}{ testing } \\
\hline & & Hidden Layer & Layer output & RMSE & $\mathrm{R}$ & RMSE & $\mathrm{R}$ \\
\hline Shelf life & $1-10-8$ & Hyperbolic tangent & Linear & 1.4 & 92.6 & 1.1 & 94.9 \\
\hline
\end{tabular}

\section{CONCLUSION}

To select the preferred formula, RSM software was used for the sensitivity evaluation and analyzing the results, arriving at the resultant best formula of a $67 \%$ surimi $+37 \%$ chicken meat burger. The quality changes in the selected formula which was studied for 27 days at $2{ }^{\circ} \mathrm{C}$. Microbiological study of the formula indicated that the aerobic packing condition without essence for 6 days was acceptable, while aerobic packing with essential oil could not pass the standard for acceptability and remained stable up to 9 days. Interestingly, the chemical analysis did not pass as far as acceptable limit until the finishing of the
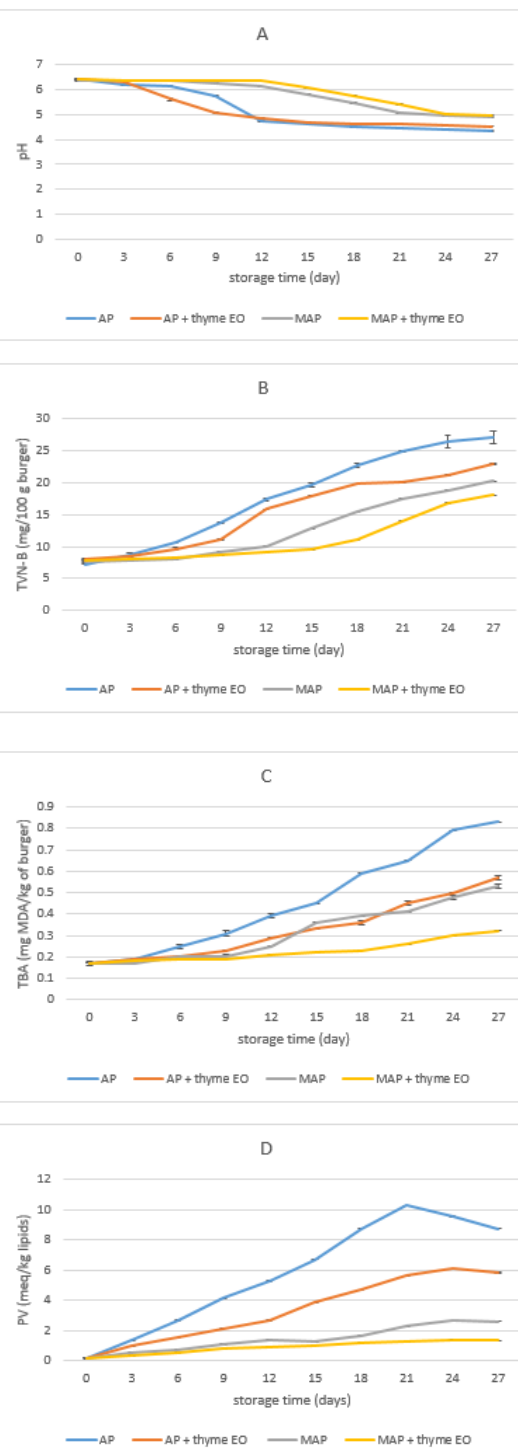

Figure 3 Effect of MAP and thyme EO on (A) pH, (B) TVN-B (mg/100 g burger), (C) TBA (mg MDA/kg of burger) and (D) PV (meq/kg lipids) of burgers at refrigeration temperature. Values are the mean of three replications \pm standard deviation.

\section{Neural network}

In order to optimize the structure of neural network and predict the shelf life of produced burgers under thyme essential oil and MAP influences, Perceptron neura network algorithm with a hidden layer was used. The network structure, including the number of neurons and training parameters of the optimal neural network and it is presented in table 1. High estimations of correlational coefficient and low RMSE indicate the efficiency of the artificial neural network model in predicting the shelf life for produced burgers. Artificial neural network model shows the superiority of this model in forecasting the termination of delivered burgers under thyme essential oil and MAP impact. MAP; therefore, the time span of consolidated burger during 18 days combined through MAP packing and thyme EO was increased. The blended utilization of MAP and thyme EO affect synergistically on expanding the shelf life of fresh formulated burgers. Overall, the results of this research indicate surimi-optimized production of burger as an appropriate option for the industry to deliver products like fresh meat. Also, the shelf life of burgers created from surimi and minced chicken can be extended by using EOs and effective packing. Also, the mode obtained from ANN had a higher correlation coefficient and less RMSE in 
predicting the shelf life of produced burgers under thyme essential oil and MAP effect.

Acknowledgments: Financial support provided by Shahid Chamran University of Ahvaz is duly gratefully acknowledged.

\section{REFERENCES}

AOAC 2010. Official methods of analysis of AOAC International; 18th ed. Gaithersburg: Association of Official Analytical Chemists.

APHA 2015. Compendium of Methods for the Microbiological Examination of Foods. 5nd ed. American Public Health Association, Washington D.C.

Babji, Y. \& Murthy, T. R. K. 2000. Effect of inoculation of mesophilic lactic acid bacteria on microbial and sensory changes of minced goat meat during storage under vacuum and subsequent aerobic storage. Meat science, 54(2), 197202.http://doi.org/10.1016/S0309-1740(99)00101-1

Behnam, B. \& Aliakbarlou, J. 2014. Antioxidant effects of Zataria multiflora and Mentha longifolia essential oils on chicken meat stored at $4^{\circ} \mathrm{C}$. Journal of Food Research, 23(4), 533-543.

Bentis, C. A., Zotos, A. \& Petridis, D. 2005. Production of fish-protein products (surimi) from small pelagic fish (Sardinops pilchardusts), underutilized by the industry. Journal of Food Engineering, 68, 303308.http://doi.org/10.1016/j.jfoodeng.2004.06.003

Burt, S. 2004. Essential oils: their antibacterial properties and potential applications in foods - a review. International Journal of Food Microbiology, 94, 223-253.https://doi.org/10.1016/j.ijfoodmicro.2004.03.022

Busatta, C., Vidal, R. S., Popiolski, A. S., Mossi, A. J., Dariva, C., Rodrigues, M. R. A., Corazzaa, F. C., Corazzaa, M. L., Vladimir Oliveira, J. \& Cansian, R. L. 2008. Application of Origanum majorana L. essential oil as an antimicrobial agent in sausage. Food Microbiology, 25(1), 207211.http://doi.10.1016/j.fm.2007.07.003

Chaijan, M., Benjakul, S., Visessanguan, W. \& Faustman, C. 2006. Changes of lipids in sardine (Sardinella gibbosa) muscle during iced storage. Food Chemistry, 99(1), 83-91. https://doi.org/10.1016/j.foodchem.2005.07.022.

Coban, Ö. E. \& Kelestemur, G. T. 2016. Qualitative improvement of catfish burger using Zataria multiflora Boiss.essential oil. Journal of Food Measurement and Characterization, 1-8.http://doi.org/10.1007/s11694-016-9420-2

Daniel, A. P., Veeck, A. P. L., Klein, B., Ferreira, L. F., da Cunha, M. A., Parodi, T. V., Schmidt, D., O. Caron, B., M. Heinzmann, B., Emanuelli, T. \& Baldisserotto, B. 2014. Using the essential oil of Aloysia triphylla (L'Her.) Britton to sedate silver catfish (Rhamdia quelen) during transport improved the chemical and sensory qualities of the fish during storage in ice. Journal of Food Science, 79(6), 1205-1211.http://doi.10.1111/1750-3841.12463

Dey, S. \& Dora, K. 2010. Effect of sodium lactate as cryostabilizer on physicchemical attributes of croaker (Johnius gangeticus) muscle protein. Journal of Food Science and Technology, 47(4), 432-436.http://doi.org/10.1007/s13197010-0071-8

Doulgeraki, A. I., Paramithiotis, S., Kagkli, D. M. \& Nychas, G. J. E. 2010. Lactic acid bacteria population dynamics during minced beef storage under aerobic or modified atmosphere packaging conditions. Food Microbiology, 27, 10281034.http://doi.org/10.1016/j.fm.2010.07.004

Frangos, L., Pyrgotou, N., Giatrakou, V., Ntzimani, A. \& Savvaidis, I. N. 2010. Combined effects of salting, oregano oil and vacuum-packaging on the shelf-life of refrigerated trout fillets. Food Microbiology, 27(1), 115121.http://doi.10.1016/j.fm.2009.09.002

Fratianni, F., De Martino, L., Melone, A., De Feo, V., Coppola, R. \& Nazzaro, F. 2010. Preservation of chicken breast meat treated with thyme and balm essential oils. Journal of Food Science, 75(8).http://doi.org/10.1111/j.17503841.2010.01791.x

Giarratana, F., Muscolino, D., Beninati, C., Ziino, G., Giuffrida, A. \& Panebianco, A. 2016. Activity of R (+) limonene on the maximum growth rate of fish spoilage organisms and related effects on shelf-life prolongation of fresh gilthead sea bream fillets. International Journal of Food Microbiology, 237, 109113. https://doi.org/10.1016/j.ijfoodmicro.2016.08.023

Gomes, H. D. A., Silva, E. N. D., Nascimento, M. R. L. D. \& Fukuma, H. T. 2003. Evaluation of the 2-thiobarbituric acid method for the measurement of lipid oxidation in mechanically deboned gamma irradiated chicken meat. Food Chemistry, 80(3), 433-437.http://doi.org/10.1016/S0308-8146(02)00499-5

Heydari, F., Varidi, M. J., Varidi, M. \& Mohebbi, M. 2016. Study on quality characteristics of camel burger and evaluating its stability during frozen storage. Journal of Food Measurement and Characterization, 10(1), 148155.http://doi.org/10.1007/s11694-015-9288-6

Jafarpour, A. \& Gorczyca, E. M. 2008. Alternating Techniques for Producing a Quality Surimi and Kamaboko from Common Carp (Cyprinus carpio). Journal of Food Science, , 73, 415- 424.http://doi.org/10.1111/j.1750-3841.2008.00937.x Jayawardana, B. C., Liyanage, R., Lalantha, N., Iddamalgoda, S. \& Weththasinghe, P. 2015. Antioxidant and antimicrobial activity of drumstick (Moringa oleifera) leaves in herbal chicken sausages. LWT-Food Science and Technology, 64(2), 1204-1208.http://doi.10.1016/j.1wt.2015.07.028
Karthikeyan, M., Dileep, A. O. \& Shamasundar, B. A. 2006. Effect of water washing on the functional and rheological properties of proteins from threadfin bream (Nemipterus japonicus) meat. International journal of Food Science \& Technology, 4, 1002-1010.http://doi.org/10.1111/j.1365-2621.2006.01122.x

Kilinc, B., Cakli, S. \& Tolasa, S. 2008. Quality changes of sardine (Sardina pilchardus) patties during refrigerated storage. Journal of Food Quality, 31(3), 366-381.http://doi.org/10.1111/j.1745-4557.2008.00205.x

Köse, S., Boran, M. \& Boran, G. 2006. Storage properties of refrigerated whiting mince after mincing by three different methods. Food chemistry, 99(1), 129135.http://doi.org/10.1016/j.foodchem.2005.06.047

Marotta, S. M., Giarratana, F., Parco, A., Neri, D., Ziino, G., Giuffrida, A. \& Panebianco, A. 2016. Evaluation of the antibacterial activity of bergamot essential oils on different Listeria monocytogenes strains. Italian Journal of Food Safety, 5(4).http://doi.10.4081/ijfs.2016.6176

Muhlisin, S. M. K., Choi, W. H., Lee, K. T., Cheong, S. H. \& Lee, S. K. 2013. The effect of modified atmosphere packaging and addition of rosemary extract, sodium acetate and calcium lactate mixture on the quality of pre-cooked hamburger patties during refrigerated storage. Asian-Australasian Journal of Animal Sciences, 26, 134.http://doi. [10.5713/ajas.2012.12468]

Namir, M., Siliha, H. \& Ramadan, M. F. 2015. Fiber pectin from tomato pomace: characteristics, functional properties and application in low-fat beef burger Journal of Food Measurement and Characterization, 9, 305312.http://doi.org/10.1007/s11694-015-9236-5

Ojagh, S. M., Rezaei, M., Razavi, S. H. \& Hosseini, S. M. H. 2010. Effect of chitosan coatings enriched with cinnamon oil on the quality of refrigerated rainbow trout. Food Chemistry, 120(1),

198.http://doi.org/10.1016/j.foodchem.2009.10.006

Patsias, A., Chouliara, I., Badeka, A., Savvaidis, I. N. \& Kontominas, M. G. 2006 Shelf life of a chilled precooked chicken product stored in air and under modified atmospheres: microbiological, chemical and sensory attributes. Food Microbiology, 23, 423-429.http://doi.org/10.1016/j.fm.2005.08.004

Petrou, S., Tsiraki, M., Giatrakou, V. \& Savvaidis, I. N. 2012. Chitosan dipping or oregano oil treatments, singly or combined on modified atmosphere packaged chicken breast meat. International Journal of Food Microbiology, 156, 264 271.http://doi.doi.org/10.1016/j.ijfoodmicro.2012.04.002

Praneetha, S. S., Dhanapal, K., Reddy, G. V. S. \& Balasubramanian, A. 2015. Development of fish finger from rohu (labeo rohita) and its quality evaluation during refrigerated storage condition. International Journal of Science, Environmental and Technology, 4, 1457-1468.

Raharjo, S. \& Sofos, J. N. 1993. Methodology for measuring malonaldehyde as a product of lipid peroxidation in muscle tissues: A review. Meat Science, 35(2), 145-169. https://doi.org/10.1016/0309-1740(93)90046-K

Rawdkuen, S., Sai-Ut, S., Khamsorn, S., Chaijan, M. \& Benjakul, S. 2009. Biochemical and gelling properties of tilapia surimi and protein recovered using an acid-alkaline process. Food Chemistry, 112, 112 119.http://doi.org/10.1016/j.foodchem.2008.05.047

Sajed, H., Sahebkar, A. \& Iranshahi, M. 2013. Zataria multiflora Boiss. (Shirazi thyme)_An ancient condiment with modern pharmaceutical uses. Journal of Ethnopharmacology, 145, 686-698.http://doi.org/10.1016/j.jep.2012.12.018

Sarıçoban, C. \& Yilmaz, M. T. 2014. Effect of thyme/cumin essential oils and butylated hydroxyl anisole/butylated hydroxyl toluene on physicochemical properties and oxidative/microbial stability of chicken patties. Poultry Science, 93(2), 456-463. https://doi.org/10.3382/ps.2013-03477

Selani, M. M., Shirado, G. A. N., Margiotta, G. B., Saldaña, E., Spada, F. P., Piedade, S. M. S., Contreras-Castillo, C. G. J. \& Canniatti-Brazaca, S. 2016 Effects of pineapple byproduct and canola oil as fat replacers on physicochemica and sensory qualities of low-fat beef burger. Meat Science, 112, 6976.http://doi.org/10.1016/j.meatsci.2015.10.020

Skandamis, P. \& Nychas, G. J. E. 2002. Preservation of fresh meat with active and modified atmosphere packaging conditions. International Journal of Food Microbiology, 79, 35-45.http://doi.org/10.1016/S0168-1605(02)00177-0

Soni, A., Gurunathan, K., Mendiratta, S. K., Talukder, S., Jaiswal, R. K. \& Sharma, H. 2018. Effect of essential oils incorporated edible film on quality and storage stability of chicken patties at refrigeration temperature $\left(4 \pm 1^{\circ} \mathrm{C}\right)$. Journal of Food Science and Technology, 55(9), 3538-3546. https://doi.org/10.1007/s13197-018-3279-7

Stevanović, Z. D., Bošnjak-Neumüller, J., Pajić-Lijaković, I., Raj, J. \& Vasiljević, M. 2018. Essential oils as feed additives-future perspectives. Molecules, 23(7), 1717.http://doi.10.3390/molecules23071717

Van Haute, S., Raes, K., Devlieghere, F. \& Sampers, I. 2017. Combined use of cinnamon essential oil and MAP/vacuum packaging to increase the microbial and sensorial shelf life of lean pork and salmon. Food Packaging and Shelf Life, 12, 51-58.http://doi.org/10.1016/j.fpsl.2017.02.004

Vanitha, M., Dhanapal, K. \& Reddy, G. V. S. 2015. Quality changes in fish burger from Catla (Catla Catla) during refrigerated storage. Journal of Food Science and Technology, 52(3), 1766-1771.http://doi.10.1007/s13197-013-1161-1

Vanitha, M., Dhanapal, K., Sravani, K. \& Reddy, G. V. S. 2013. Quality evaluation of value added mince based products from catla (Catla catla) during 
frozen storage. International Journal of Science, Environmental and Technology, 2, 487-501.

Zakipour Rahimabadi, E. \& Divband, M. 2012. The Effects of Coating and Zataria multiflora Boiss Essential Oil on Chemical Attributes of Silver Carp Fillet Stored at $4^{\circ} \mathrm{C}$. International Food Research Journal, 19(2), 685-690.

Zamuz, S., López-Pedrouso, M., Barba, F. J., Lorenzo, J. M., Domínguez, H. \& Franco, D. 2018. Application of hull, bur and leaf chestnut extracts on the shelflife of beef patties stored under MAP: Evaluation of their impact on physicochemical properties, lipid oxidation, antioxidant, and antimicrobial potential. Food Research International, 112, 263273.http://doi.10.1016/j.foodres.2018.06.053 